\title{
MEDICAL TOURISM IN THE EYES OF THE STUDENTS
}

\author{
Mariana Albert, Beni Asanova \\ Medical College "J. Filaretova", Medical University - Sofia
}

\begin{abstract}
INTRODUCTION: The high production rate and the introduction of modern technologies in all spheres of human activity have become a prerequisite for the development of chronic hypodynamia and the increasing mental stress. Medical tourism is a wonderful way of improving the health state of those in need belonging to various age groups, locals or foreigners, using the rich natural and geographical resources of our country. For quality customer service the specific vocational training of rehabilitators is of essential significance.

AIM: To determine through a questionnaire survey whether students are familiar with the current trends of this new sector in providing health services and whether they want to work in the field of medical tourism.

MATERIALS AND METHODS: Second- and third-year students majoring in rehabilitation at the Medical College "Y. Filaretova", Sofia were the target of the study.

RESULTS: The results showed that the students are actively interested in the innovations and $45 \%$ of them would work in the field of medical tourism with permanent employment, good payment and standardized working hours.
\end{abstract}

CONCLUSIONS: Important conclusions about medical tourism through the eyes of students have been drawn.

Keywords: rehabilitators, medical tourism, working hours

\section{INTRODUCTION}

The technological progress and the rapid development of information technology have changed the way of life of all people. The utilization of computers in all spheres has created prerequisites for hypodynamia and an increasing number of diseases. Of all the age groups the highest risk group is young people who stay for hours in front of computers and mobile phones $(1,2,5)$. The rich natural resources of our country are an excellent basis for the development of health and medical tourism. It may play a significant

\footnotetext{
Address for correspondence:

Mariana Albert

Medical College "Y. Filaretova"

Medical University of Sofia

3 Yordanka Filaretova St.

1606 Sofia

e-mail:andial@mail.bg
}

role in contributing to improve the health of the population through the use of natural resources on the one hand and opening of new jobs for young medical professionals on the other. They have the opportunity to develop and expand their career in SPA, Wellness, Thalassotherapy and MedSPA centers, offering treatments and services with preventive and curative purpose in a comfortable environment $(3,4)$.

\section{AIM}

To determine through a questionnaire survey whether students are familiar with the current trends of this new sector in providing health services and whether they want to work in the field of medical tourism.

\section{MATERIALS AND METHODS}

The survey was conducted in the period MarchMay, 2016. The object of study were the second- and 
Mariana Albert, Beni Asanova

third-year students enrolled in the Rehabilitator program - 71 students from the Medical College "Yordanka Filaretova", Medical University - Sofia. The average age of the students was 25.3 years. Like most disciplines in which women predominate, among rehabilitators the ratio was $38 \%$ males and $62 \%$ females. A sociological study was conducted by a questionnaire survey method.

\section{RESULTS AND DISCUSSION}

The survey shows that the majority of students prefer to work in the health care system $-39.6 \%$. Work in private practices was ranked second by students $39 \%$. The general opinion is that these employees receive the best payment, despite the extended working hours. Only $14 \%$ of them would work in spa hotels. Interest in working in fitness centers has the lowest results $-7.4 \%$ (Table 1 ).

Table 1. Preferred workplace

\begin{tabular}{|c|c|c|c|}
\hline Healthcare & Spa Hotels & $\begin{array}{l}\text { Private } \\
\text { practice }\end{array}$ & $\begin{array}{l}\text { Fitness } \\
\text { Centers }\end{array}$ \\
\hline $39.6 \%$ & $14 \%$ & $39 \%$ & $7.4 \%$ \\
\hline
\end{tabular}

To the question "What additional knowledge and skills would you like to acquire?", students put first the study of different types of massage - 52.1\%; PNF was second - $24 \%$. They gave the eastern medical practices third ranking - $14 \%$. A small part of students were interested in kinesio taping and the methods of Bobath - 9.9.\% (Figure 1).

For the question "In what form do you want to obtain additional knowledge and skills?" students were able to choose multiple answers. Increased knowledge through various elective disciplines in-

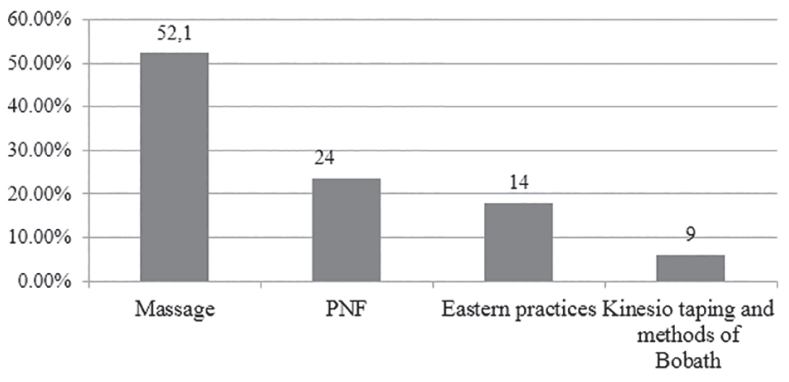

Figure 1. Results of the question "What additional knowledge and skills would you like to acquire?" cluded in the curricula was chosen by 21.3 percent of the respondents. Continuing education and knowledge through the acquisition of a Master's degree was the reply of $30.9 \%$ of the participants. The biggest group was $47.8 \%$ of the students who chose to attend specialized courses (Figure 2).

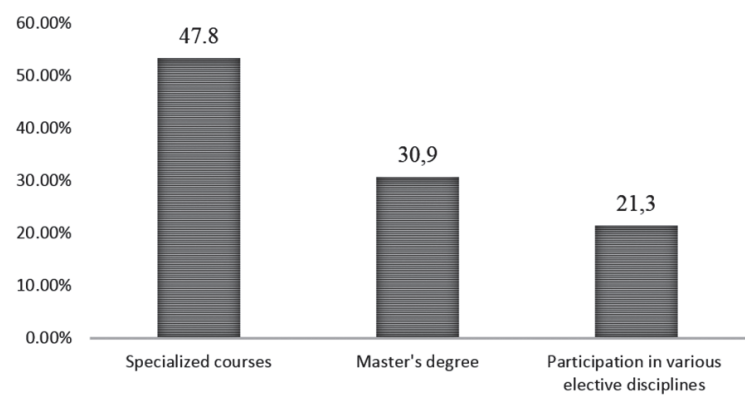

Figure 2. Results of the question "In what form do you want to obtain additional knowledge and skills?"

As for the open question: "Why do you not want to work in a spa hotel?", the survey shows a good trend, only $2.8 \%$ of the students have pointed out bad working conditions. The results show that students have placed second long working hours with $12.7 \%$ and the first reason is seasonal work with $84.5 \%$ (Figure 3).

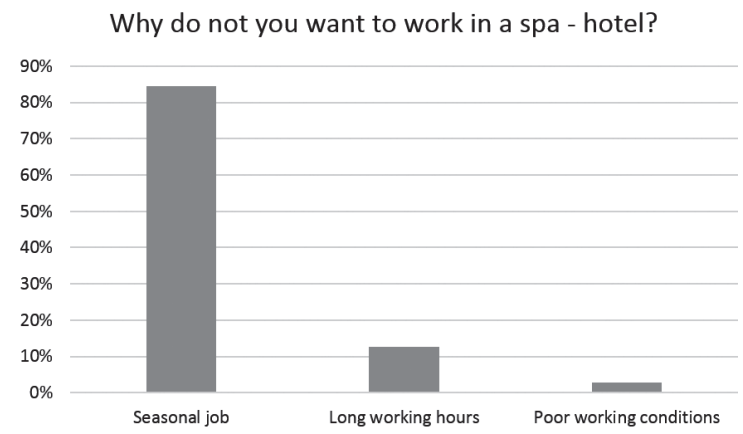

Figure 3. Results of the question "Why do you not want to work in a spa - hotel?"

A key question in the survey was "Why would you work in the health and medical tourism?" A small number of students - 15.6 percent believe that medical tourism allows them to work in their native places. Better payment is a reason for 39.4 percent of the respondents. The highest rate - $45 \%$ of them pre- 
fer working with healthy people and in a comfortable environment (Figure 4).

Why would you worke in the health and medical tourism?

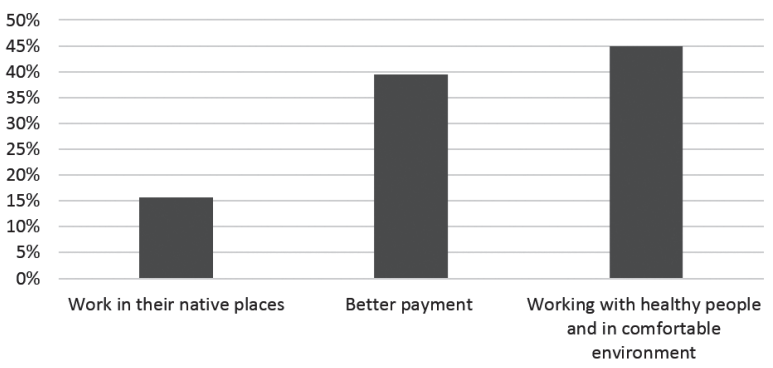

Figure 4. Results of the question "Why would you work in the health and medical tourism?"

The data obtained from the survey show that young people are well oriented in the economic situation. They monitor the progress of the sphere and show interest in enhancing their professional development, search for ways and means to improve the working conditions. They are well aware of novelties and try to participate actively in various events.

The results give us a reason to believe that $45 \%$ of the new generation of rehabilitators will actively participate and work to enhance the professionalism and develop competitive specialists in the health and medical tourism.

The majority of them $47.8 \%$ believe that the best way to achieve professional development is attending specialized courses and for $31 \%$ it is having a Master's degree.

Providing a permanent job in hotels is the best prerequisite for retaining staff. The younger generation is more demanding in terms of working conditions and prefers working in a comfortable atmosphere.

\section{CONCLUSION}

The favorable natural and geographical resources of Bulgaria enable it to develop medical and health tourism. The aging population in Europe and around the world gives us new opportunities to establish our country as a desirable destination for health and medical tourism. Providing year-round staff in SPA, Wellness, Thalassotherapy and MedS-
PA centers will ensure new workplaces and improve the economic situation of the country.

\section{REFERENCES}

1. Annual report on youth. Ministry of Youth and Sports, 2005 Available at: http://www.mon.bg/ opencms/

2. Albert M, Yanev St. Traditions and innovations in the training of qualified personnel for medical and health tourism. Sofia Euroregion, business and eurointegration. $2016 ; 31$.

3. Lee IM, Shiroma EJ, Lobelo F, Puska P, Blair SN, Katzmarzyk PT. Effect of physical inactivity on major non- communicable diseases worldwide: an analysis of burden of disease and life expectancy. Lancet; 2012.380 (9838): 219-229.

4. U.S. Department of Health and Human Services. Physical Activity and Health: A Report of the Surgeon General. 1996. https://www.cdc.gov/nccdphp/ sgr/pdf/sgrfull.pdf

5. WHO. Global strategy on diet, physical activity and health. Geneva: World Health Organization, 2004, http://www.who.int/dietphysicalactivity/ strategy/eb11344/strategy_english_wcb.pdf. 